\title{
Papers
}

\section{Model of outcomes of screening mammography: information to support informed choices}

\author{
Alexandra Barratt, Kirsten Howard, Les Irwig, Glenn Salkeld, Nehmat Houssami
}

\begin{abstract}
Objective To provide easy to use estimates of the benefits and harms of biennial screening mammography for women aged $40,50,60$, and 70 years.

Design Markov process model, with data from BreastScreen Australia, the Australian Institute of Health and Welfare, and the Australian Bureau of Statistics.

Main outcome measure Age specific outcomes expressed per 1000 women over 10 years.

Results For every 1000 women screened over 10 years, 167-251 (depending on age) receive an abnormal result; 56-64 of these women undergo at least one biopsy, 9-26 have an invasive cancer detected by screening, and 3-6 have ductal carcinoma in situ (DCIS) detected by screening. More breast cancers (both invasive and DCIS) are diagnosed among screened than unscreened women. For example, among 1000 women aged 50 who have five biennial screens, 33 breast cancers are diagnosed: 28 invasive cancers (18 detected at screening and 10 interval cancers) and five DCIS (all detected at screening). By comparison, among 1000 women aged 50 who decline screening, 20 cancers are diagnosed over 10 years. There are about $0.5,2,3$, and 2 fewer deaths from breast cancer over 10 years per 1000 women aged $40,50,60$, and 70 , respectively, who choose to be screened compared with women who decline screening at times determined by relevant policy. Conclusion Benefits and harms of screening mammography are relatively finely balanced. Quantitative estimates such as these can be used to support individual informed choices about screening.
\end{abstract}

\section{Introduction}

Screening mammography is recommended for women aged 50-69 on the evidence that benefits outweigh harms. ${ }^{12}$ The issue remains controversial, however, especially for women outside this age group. According to the General Medical Council, ${ }^{3}$ the UK National Screening Committee, ${ }^{4}$ and others ${ }^{5}$ comprehensive information about screening should be available to support informed choices. General principles on the provision of information about cancer screening include that information should be balanced (describing benefits and harms over a similar time frame, such as 10 years) and that estimates should be presented with a constant denominator (such as per 100 or 1000 people). ${ }^{6}$ Important harms include anxiety, which can be long lasting, generated by false positive results, ${ }^{7}$ and the psychological and physical impact of detection and treatment of disease that would not have been diagnosed without screening (overdetection or detection of inconsequential disease). ${ }^{8}$
We developed a model of screening mammography for women aged 40 to 79 . We constructed it so that outcomes are presented per 1000 women of ages 40, 50, 60 and 70 years who choose to be screened at times relevant to policy. Biennial screening mammography (using two view mammography and double reading of films) has been provided in Australia for more than a decade, targeting women aged $50-69$ by advertising and letters of invitation. ${ }^{1}$ Women aged 40-49 and those aged 70-79 may also be screened in the programme. Thus the major decision points for women are at age 40 , when they can choose to begin screening or not; at age 50 , when they will be invited to screening up to the age of 69 ; and at age 70 , when they may choose to continue or cease screening.

Clearly, women can make additional choices at any time to drop in or out of screening, but these are the common decision points under existing policy.

\section{Methods}

We constructed a Markov process model for two hypothetical cohorts. In one cohort women undergo biennial screening over 10 years and in the other cohort they do not (table 1). The model is based on $100 \%$ participation in the screening cohort and no participation in the non-screening cohort and thus generates the consequences for women who attend screening regularly versus those who decline it. The first scenario compares women who start screening at age 40 with women who decline screening at age 40 (to estimate the effect of starting screening early). The second and third scenarios model outcomes for women who choose to start screening at age 50 and then continue over the full life of the screening programme-that is, from 50-69 years. As this decision will hold for 20 years, the second scenario provides outcomes for the first 10 years, and the third scenario provides outcomes for the second 10 years of this choice. The last scenario compares outcomes among women aged 70 who have been screened regularly and then choose to continue screening for another 10 years with women who stop screening at 69 years (to estimate the effect of extending screening to 79 years).

\section{Data sources and assumptions}

The box summarises data sources and assumptions underlying the model.

\section{Incidence of breast cancer in screened women and other} immediate outcomes of screening

We used data from BreastScreen Australia ${ }^{9-13}$ to populate the model. These data comprise outcome information for screening

The formula used to calculate mortality from breast cancer in unscreened women is on bmj.com 


\begin{tabular}{|c|c|}
\hline Screening strategy & Comparator \\
\hline $\begin{array}{l}1000 \text { women who begin screening at age } 40 \\
\text { and have five biennial screens (from } 40-49 \\
\text { years) }\end{array}$ & $\begin{array}{l}\text { No screening over same time period (that is, } \\
\text { from ages } 40-49 \text { ) }\end{array}$ \\
\hline $\begin{array}{l}1000 \text { women who begin screening at age } 50 \\
\text { and have five biennial screens (from } 50-59 \\
\text { years) }\end{array}$ & $\begin{array}{l}\text { No screening over same time period (that is, } \\
\text { from ages 50-59, having also previously } \\
\text { declined screening at } 40 \text { ) }\end{array}$ \\
\hline $\begin{array}{l}1000 \text { women aged } 60 \text {, who now have a } \\
\text { further five biennial screens (from } 60-69 \\
\text { years) having been screened biennially } \\
\text { from } 50\end{array}$ & $\begin{array}{l}\text { No screening over same time period (that is, } \\
\text { from } 60-69 \text { years, having also previously } \\
\text { declined screening at } 40 \text { and } 50 \text { ) }\end{array}$ \\
\hline $\begin{array}{l}1000 \text { women aged } 70, \text { who now have a } \\
\text { further five biennial screens (from } 70-79 \\
\text { years) having been screened biennially } \\
\text { from } 50\end{array}$ & $\begin{array}{l}\text { Stop at } 69 \text {, having previously been screened } \\
\text { from } 50-69 \text { years }\end{array}$ \\
\hline
\end{tabular}

and subsequent tests for more than 1.25 million women screened each year. To minimise variation from year to year, we pooled the most recent five years (1997-2001) of data. For each screen, we obtained the numbers of breast cancers detected (invasive and ductal carcinoma in situ, DCIS), women recalled for extra imaging and biopsy, and interval cancers (0-12 months and 12-24 months) after a screen.

\section{Incidence of breast cancer in unscreened women}

We used the model developed by Taylor and Boyages for the age specific incidence of breast cancer in unscreened women. ${ }^{14}$ We estimated age specific incidence for DCIS by assuming that $2 \%$ of breast cancer diagnosed clinically in unscreened women is DCIS, on the basis of rates of DCIS reported before screening. ${ }^{15}$

\section{Mortality from breast cancer in unscreened women}

We used data on mortality from breast cancer for the five most recent years of national data from Australian Institute of Health and Welfare. ${ }^{9}{ }^{10}$ As these data include both women who did and did not undergo screening, we adjusted them using age specific screening participation rates over the same time period ${ }^{9}{ }^{10}$ to obtain mortality for unscreened women (see appendix on bmj.com).

\section{Data sources and assumptions}

Data (from BreastScreen Australia unless stated otherwise) Participation in screening ${ }^{910}$

Invasive breast cancer detected by screening ${ }^{9}$

Ductal carcinoma in situ (DCIS) detected by screening ${ }^{9}$

Recall rates ${ }^{10}$

Type of recall procedure ${ }^{11-13}$

Interval cancer rate (0-12 and 13-24 months $)^{9}{ }^{10}$

Overall incidence of and mortality from breast cancer ${ }^{910}$ Incidence of breast cancer in unscreened women (model by Taylor and Boyages ${ }^{14}$ )

Mortality from all causes (Australian Bureau of Statistics age specific mortality 2001)

\section{Assumptions}

Incidence of DCIS in unscreened women (assumed to be $2 \%$ of total incidence of breast cancer in unscreened women ${ }^{15}$ )

Size of benefit on breast cancer mortality due to screening (relative risk reduction of $37 \%$ for women aged $50-79^{16} 17$ and $23 \%$ for women $40-49^{17}{ }^{18}$ )

Onset and duration of benefit on breast cancer mortality (benefit accrues linearly to maximal level over first five years after starting screening; benefit declines linearly to nothing over five years after stopping screening)

Mortality from causes other than breast cancer (screened and unscreened women experience the same risk of death from causes other than breast cancer)

\section{Mortality from breast cancer in screened women}

Among 50-69 year old women, screening mammography reduces the risk of death from breast cancer by about $25 \%{ }^{16}{ }^{17}$ As this figure is attenuated by non-compliance, we used a relative risk reduction of $37 \%$ (95\% confidence interval $21 \%$ to $49 \%),{ }^{17}$ which includes adjustment for full participation to represent the effect for women who actually attend screening. We used the same relative risk reduction for women $>70$. In sensitivity analyses, we tested the effect of varying the relative risk reduction over the approximate range of the $95 \%$ confidence interval reported by Glasziou (20\% to $50 \%) .{ }^{17}$ For women aged $40-49$ screening mammography may reduce mortality from breast cancer by $15 \%$; we used a reduction of $23 \%$, adjusted for compliance. ${ }^{18}$

As the benefit of screening on mortality is not immediate we assumed that such benefit accumulates linearly over five years from the start of screening, and, similarly, we assumed that the benefit declines linearly over the five years after screening ceases.

We applied the relative risk reductions to the age specific mortality from breast cancer for unscreened women to derive the rates for screened women.

\section{Mortality due to causes other than breast cancer}

We used data from the Australian Bureau of Statistics for age specific all cause mortality. These rates were split into mortality from breast cancer and from causes other than breast cancer. Rates for causes other than breast cancer for screened and unscreened women were fixed at the age specific rate for unscreened women. We applied these rates to the cohort at risk in each given year to calculate the number of deaths from causes other than breast cancer in screened and unscreened women. All rates were converted to annual probabilities.

\section{All cause mortality}

We calculated the total number of deaths in each year by summing the number of deaths due to breast cancer with the number of deaths due to causes other than breast cancer.

\section{Progression through the model}

Each scenario begins with a defined number of women (1000) at a specified starting age. We then apply age specific probabilities to reflect the likely transition of the cohorts through 10 one year cycles.

\section{Effect of comorbidity}

We also estimated the impact of comorbidity on outcomes as participants in excellent health can expect to gain more from screening, particularly at older ages when competing causes of death increase. We used estimates for mortality according to self reported health status in four categories (excellent, good, fair, or poor). ${ }^{19}$ Using the combined category of good or fair health as the base case, we compared outcomes for women in poor health and for women in excellent health by using rates for women seven years older or five years younger. ${ }^{19}$

\section{Results}

Outcomes of screening over 10 years for women aged 40, 50, 60 , and 70

Table 2 shows results for all age groups. Using 50 year old women as an example for interpretation, among 1000 women aged 50 who are screened biennially over the next 10 years, 242 will receive an abnormal result and be recalled for assessment. Of these, 178 will have only more imaging and 64 will undergo biopsy. Therefore, over 10 years there is a $24 \%$ chance of being recalled and a $6 \%$ chance of having at least one breast biopsy. A total of 23 cancers will be detected by screening (18 invasive and 
Table 2 Outcomes for women who undergo screening compared with those who do not. Figures are cumulative number out of 1000 women over 10 years

\begin{tabular}{|c|c|c|c|c|c|c|c|c|}
\hline \multirow[b]{2}{*}{ Event over 10 years } & \multicolumn{2}{|l|}{ Age 40} & \multicolumn{2}{|l|}{ Age 50} & \multicolumn{2}{|c|}{ Age 60} & \multicolumn{2}{|c|}{ Age 70} \\
\hline & $\begin{array}{l}\text { Begin screening at } \\
\text { age } 40 \text {, five biennial } \\
\text { screens }\end{array}$ & No screening & $\begin{array}{l}\text { Begin screening at } \\
\text { age } 50 \text {, five biennial } \\
\text { screens }\end{array}$ & No screening & $\begin{array}{c}\text { Have five more } \\
\text { biennial screens }\end{array}$ & No screening & $\begin{array}{c}\text { Have five more } \\
\text { biennial screens }\end{array}$ & $\begin{array}{c}\text { Finish } \\
\text { screening at } \\
\text { age } 69\end{array}$ \\
\hline Are recalled for more tests & 250.9 & & 242.0 & & 184.6 & & 166.6 & \\
\hline \multicolumn{9}{|l|}{ Recalled for: } \\
\hline $\begin{array}{l}\text { Extra imaging only } \\
\text { (clinical examination } \\
\text { plus mammography } \\
\text { and/or ultrasound) }\end{array}$ & 191.4 & & 177.9 & & 128.6 & & 110.2 & \\
\hline $\begin{array}{l}\text { Biopsy (total having at } \\
\text { least one biopsy) }\end{array}$ & 59.5 & & 64.1 & & 56.0 & & 56.4 & \\
\hline $\begin{array}{l}\text { Fine needle aspiration } \\
\text { biopsy }\end{array}$ & 31.7 & & 30.5 & & 25.4 & & 25.4 & \\
\hline Core biopsy & 21.7 & & 27.2 & & 25.3 & & 25.8 & \\
\hline Open biopsy & 6.1 & & 6.4 & & 5.3 & & 5.2 & \\
\hline $\begin{array}{l}\text { Invasive breast cancer } \\
\text { detected at screening }\end{array}$ & 8.5 & & 17.6 & & 23.3 & & 26.4 & \\
\hline Develop interval cancer & 9.1 & & 10.4 & & 9.2 & & 8.8 & \\
\hline $\begin{array}{l}\text { Diagnosis of invasive } \\
\text { breast cancer }\end{array}$ & 17.6 & 13.2 & 28.1 & 19.8 & 32.5 & 23.9 & 35.1 & 25.1 \\
\hline $\mathrm{DClS}^{*}$ & 3.4 & 0.3 & 4.9 & 0.4 & 5.5 & 0.5 & 5.7 & 0.5 \\
\hline $\begin{array}{l}\text { Breast cancer diagnosis of } \\
\text { any kind }\end{array}$ & 21.0 & 13.5 & 32.9 & 20.2 & 38.0 & 24.4 & 40.8 & 25.6 \\
\hline Die from breast cancer & 2.0 & 2.5 & 4.0 & 5.9 & 5.1 & 8.1 & 6.2 & 8.4 \\
\hline $\begin{array}{l}\text { Die from causes other } \\
\text { than breast cancer }\end{array}$ & 10.8 & 10.8 & 25.3 & 25.2 & 68.5 & 68.4 & 199.5 & 199.3 \\
\hline Total who die & 12.8 & 13.3 & 29.3 & 31.1 & 73.6 & 76.5 & 205.7 & 207.8 \\
\hline
\end{tabular}

${ }^{*}$ Ductal carcinoma in situ, detected by screening in screening group, and presenting clinically with symptoms in unscreened group.

five DCIS). A further 10 interval cancers will be diagnosed, giving a total of 33 cancers diagnosed in the screening group. In comparison, among 1000 women aged 50 who decline screening, over 10 years about 20 breast cancers (almost all of which are invasive) will be detected. Among the screened women four will die from breast cancer compared with six among the unscreened women; this is in the context of around 31 deaths from all causes in the unscreened group and 29 deaths from all causes (including breast cancer) in the screened group.

Similar interpretations apply to the other scenarios. The general pattern is the same for women who choose or decline screening at 40, although the numbers of diagnoses of breast cancer, deaths from breast cancer, and deaths from all causes are lower. For women aged 60 the pattern is again similar but with larger numbers of diagnoses, deaths from breast cancer, and deaths from all causes.

For women who continue screening into their 70 s, over 10 years two fewer women per thousand die from breast cancer than in women who stop screening (six $v$ eight deaths from breast cancer). The number of diagnoses of breast cancer in screened women is about 41 and the number in unscreened women about 26 . All cause mortality is substantially higher than in younger women, reflecting the increase in deaths from other causes.

Sensitivity analyses that varied the relative risk reductions for women over 50 across the range of $20-50 \%$ resulted in only small changes in the absolute number of deaths related to breast cancer for each age group. With a relative risk reduction of $50 \%$, the number of deaths from breast cancer in screened women decreased from 4.0 to 3.7 for 50 year olds; from 5.1 to 4.5 for 60 year olds; and from 6.2 to 5.1 for 70 year old women. Full details of the sensitivity analysis are available on request.

\section{Effect of self reported health status}

Self reported health status had little effect on incidence of or mortality from breast cancer, but, as expected, had a striking effect on the mortality from causes other than breast cancer.
Table 3 shows data for women aged 70; other results from this analysis are available on request.

\section{Discussion}

We have presented easy to use, age specific estimates of the benefits and harms of screening mammography. These estimates should give women, clinicians, and service providers full information about mammography screening. In summary, for every 1000 women screened over 10 years, 167-251 (depending on age) receive an abnormal result and are recalled; about 56-64 of these have at least one biopsy. Nine to 26 women (depending on age) have an invasive cancer detected by screening and three to six have DCIS detected by screening. About 0.5, 2, 3, and 2 fewer deaths from breast cancer occur over 10 years among 1000 women aged $40,50,60$, and 70 years respectively who choose to be screened compared with women who decline screening at these times.

\section{Strengths and limitations}

Although other models of mammographic screening exist, this is the first comprehensive use of a balance sheet approach. Furthermore our model is unique in modelling screening outcomes cumulatively over 10 years (five screening rounds) for specific age groups of women, at decision points relevant to policy. We have also considered the potential impact of comorbidity on the outcomes of screening.

There is uncertainty around the reductions in mortality attributable to screening mammography, ${ }^{216-17}$ especially for women in their $40 \mathrm{~s}$ and $70 \mathrm{~s}$. As the relative risk reduction in women $65-74$ is similar to that observed in women aged $50-64^{20}$ we used the same estimate of effect for women aged 50-79. Screening mammography, however, may be more effective now than it was at the time of the randomised trials so we conducted a sensitivity analysis using a larger relative risk reduction of $50 \%$ for women $>50$. This makes little difference to the balance of benefit and harms. 
Table 3 Outcomes over 10 years for 1000 women aged 70 who have undergone screening since age 50 and who choose to continue to be screened compared with 1000 women, previously screened, who decide to finish screening at age 69 by self rated health status. Figures are cumulative number of women out of 1000 over 10 years

\begin{tabular}{|c|c|c|c|c|c|c|}
\hline \multirow[b]{2}{*}{ Event over 10 years } & \multicolumn{2}{|c|}{ Good or fair self rated health (base case) } & \multicolumn{2}{|c|}{ Excellent self rated health } & \multicolumn{2}{|c|}{ Poor self rated health } \\
\hline & Screening & Stop screening & Screening & Stop screening & Screening & Stop screening \\
\hline Are recalled for more tests & 166.6 & & 174.3 & & 153.3 & \\
\hline \multicolumn{7}{|l|}{ Recalled for: } \\
\hline $\begin{array}{l}\text { Extra imaging only (clinical } \\
\text { examination plus } \\
\text { mammography and/or } \\
\text { ultrasound) }\end{array}$ & 110.2 & & 115.3 & & 101.4 & \\
\hline $\begin{array}{l}\text { Biopsy (total having at least } \\
\text { one biopsy) }\end{array}$ & 56.4 & & 59.0 & & 52.0 & \\
\hline Fine needle aspiration biopsy & 25.4 & & 26.5 & & 23.4 & \\
\hline Core biopsy & 25.8 & & 27.0 & & 23.8 & \\
\hline Open biopsy & 5.2 & & 5.5 & & 4.8 & \\
\hline $\begin{array}{l}\text { Invasive breast cancer detected } \\
\text { at screening }\end{array}$ & 26.4 & & 27.6 & & 24.2 & \\
\hline Develop interval cancer & 8.8 & & 9.2 & & 7.9 & \\
\hline $\begin{array}{l}\text { Diagnosis of invasive breast } \\
\text { cancer }\end{array}$ & 35.1 & 25.1 & 36.8 & 25.9 & 32.2 & 22.7 \\
\hline$\overline{\mathrm{DClS}^{*}}$ & 5.7 & 0.5 & 5.9 & 0.5 & 5.2 & 0.5 \\
\hline $\begin{array}{l}\text { Breast cancer diagnosis of any } \\
\text { kind }\end{array}$ & 40.8 & 25.6 & 42.7 & 26.5 & 37.4 & 23.2 \\
\hline Die from breast cancer & 6.2 & 8.4 & 6.4 & 8.8 & 5.6 & 7.6 \\
\hline $\begin{array}{l}\text { Die from causes other than } \\
\text { breast cancer }\end{array}$ & 199.5 & 199.3 & 117.1 & 117.0 & 410.6 & 410.2 \\
\hline Total who die & 205.7 & 207.8 & 123.5 & 125.8 & 416.2 & 417.8 \\
\hline
\end{tabular}

*Ductal carcinoma in situ detected by screening in the screening group, and presenting clinically with symptoms in the unscreened group.

Overdetection and overtreatment are important but underappreciated harms of screening. ${ }^{8}$ Increased numbers of breast cancers are diagnosed at all ages in women who choose screening. Some of this is due to increased detection of DCIS by screening and this is explicit in the model. DCIS is a non-invasive form of cancer that may or may not progress to invasive cancer. It is associated with low mortality after surgical treatment and the value of its early detection and treatment is uncertain. ${ }^{21}$

Diagnosis of invasive cancer is more common among screened women, due to lead time (earlier diagnosis generates a mortality benefit) and detection of invasive breast cancer, which, in the absence of screening, would not have been diagnosed within the remainder of the woman's lifetime (overdetection). We do not know how much of the increased detection is lead time and how much is overdetection; published estimates of the overdetection range from $2 \%$ to $30 \% .{ }^{22-24}$ Further work is required to clarify the extent of overdetection within breast screening. This is important because the effects of overdetection extend beyond living with the diagnosis of cancer and include adverse effects of treatment for breast cancer (surgery, endocrine therapy, chemotherapy, radiotherapy).

Because screening is well established in Australia, the incidence and mortality of breast cancer in the absence of screening cannot be directly measured and thus we used modelled estimates of incidence ${ }^{14}$ and estimated mortality (see appendix on bmj.com). We compared these estimates with Australian incidence and mortality statistics from before the widespread availability of mammographic screening and found that they were similar. In addition, we validated our model by comparing the 10 year incidence of breast cancer weighted for participation in screening generated by the model with the 10 year incidence of breast cancer from published national estimates.

\section{Interpretation and implications for future practice and} research

The information presented here is readily usable by women considering screening mammography. In essence the decision to be screened is a gamble; there is only a small chance of benefit but the stakes are high. Some women will be happy to choose the gamble even though they may experience anxiety, inconvenience, and physical adverse effects; other women will not. Clinicians may be able to use this information to support discussions with women about these possibilities and to support their patients in making a choice that is consistent with their own circumstances and values and preferences. As well as providing information for women aged 50-69 years, it may be useful for clinicians' discussions with patients in "out of target" age groups by making explicit the possible risks and benefits of a decision to be screened. We have incorporated these estimates into decision aids that are currently being tested in Australia. These methods can be applied to different populations and other screening contexts. The effect of such information on decision quality and screening participation is currently unknown but can be tested.

We thank Erin Mathieu for assistance with proofreading this paper.

Contributors: All authors contributed to the intellectual development of this paper. $\mathrm{AB}$ wrote the first draft and coordinated all revisions. $\mathrm{KH}$ undertook the modelling. All authors commented on drafts of the paper. All authors are guarantors.

Funding: This work was undertaken as part of the screening and test evaluation programme, funded by the National Health and Medical Research Council of Australia (grant No 211205).

Competing interests: None declared.

Ethical approval: Not required.

1 BreastScreen Australia and Australian Department of Health and Ageing. Who should have a mammogram? www.breastscreen.info.au/who/index.htm (accessed 2 Feb 2005).

2 US Preventive Services Task Force. Screening for breast cancer. www.ahrq.gov/clinic/ uspstf/uspsbrca.htm (accessed 2 Feb 2005).

3 General Medical Council. Seeking patients' consent: the ethical considerations. November 1998. www.gmc-uk.org/global_sections/search_frameset.htm (accessed 2 Feb 2005). 


\section{What is already known on this topic}

Outcomes of screening mammography include benefits (reduced risk of death from breast cancer) and harms (physical and psychological adverse effects from screening and follow-up tests and detection of inconsequential disease)

Current information about screening mammography fails to meet women's needs for full and balanced information about these benefits and harms

\section{What this study adds}

This model of screening mammography presents quantitative information about the outcomes of screening in a form suitable to inform decisions about screening

It provides information about cumulative benefits and harms over the same time frame (10 years) for women aged $40,50,60$, and 70 years who are considering screening

4 UK National Screening Committee. Second report of the UK national screening committee. www.nsc.nhs.uk/pdfs/secondreport.pdf (accessed 2 Feb 2005).

Thornton H, Edwards A, Baum M. Women need better information about routine mammography. BMJ 2003;327:101-3.

6 Barratt AL, Trevena L, Davey HM, McCaffery K. Use of decision aids to support informed choices about screening. BMJ 2004;329:507-10.

7 Drossaert CHC, Boer H, Seydel ER. Does mammographic screening and a negative result affect attitudes towards future breast screening? J Med Screen 2001;8:204-12.

8 Schwartz LM, Woloshin S, Fowler FJ, Welch HG. Enthusiasm for cancer screening in the United States. JAMA 2004;291:71-78.

9 Australian Institute of Health and Welfare. BreastScreen Australia monitoring reports 1998-99, 1999-2000 and 2000-2001. Cancer series numbers 25 and 26. Canberra: Australian Institute of Health and Welfare, 2003 (CAN 20 and CAN 21).

10 Australian Institute of Health and Welfare. BreastScreen Australia achievement report 1997-1998. Cancer series number 13. Canberra, Australian Institute of Health and Welfare, 2000 (CAN 8).
11 Queensland Health. BreastScreen Queensland annual statistical report for 1999. Brisbane: Queensland Health, 2001

12 BreastScreen Victoria. BreastScreen Victoria 2000 and 2001 annual statistical reports. Melbourne: BreastScreen Victoria, 2002-3.

13 BreastScreen SA. BreastScreen SA statistical report 1999-2000. Adelaide: BreastScreen SA, 2003.

14 Taylor R, Boyages J. Estimating the risk of breast cancer from population incidence affected by widespread mammographic screening. J Med Screen 2001;8:73-6.

15 Van Zee KJ, Liberman L, Samli B, Tran KN, McCormick B, Petrek JA, et al. Long term follow-up of women with ductal carcinoma in situ treated with breast-conserving surgery: the effect of age. Cancer 1999;86:1757-67.

16 Kerlikowske K, Grady D, Rubin SH, Sandrock C, Ernster VL. Efficacy of screening mammography: a meta-analysis. JAMA 1995;273:149-54.

17 Glasziou P. Meta-analysis adjusting for compliance: the example of screening for breast cancer. J Clin Epidemiol 1992;45:1251-6.

18 Irwig L, Glasziou P, Barratt A, Salkeld G. Review of the evidence about the value of mammographic screening in 40-49 year old women. Kings Cross, New South Wales: NHMRC National Breast Cancer Centre, 1997.

19 Welch HG, Albertsen PC, Nease RF, Bubolz TA, Wasson JH. Estimating treatment benefits for the elderly: the effect of competing risks. Ann Internal Med 1996;124:577-84.

20 Chen HH, Tabar L, Fagerberg G, Duffy SW. Effect of breast cancer screening after age 64.J Med Screen 1995;2:10-14

21 Ernster VL, Ballard-Barbash R, Barlow WE, Zheng Y, Weaver D, Cutter G, et al. Detection of ductal carcinoma in situ in women undergoing screening mammography $\mathrm{J} \mathrm{Natl}$ Cancer Inst 2002;94:1546-54.

22 Paci E, Warwick J, Falini P, Duffy SW. Overdiagnosis in screening: is the increase in breast cancer incidence rates a concern? J Med Screen 2004;11:23-7.

23 Anttila A, Koskela J, Hakama M. Programme sensitivity and effectiveness of mammography service screening in Helsinki, Finland. J Med Screen 2002; 9:153-8.

$24 \mathrm{Zahl} \mathrm{PH,} \mathrm{Strand} \mathrm{BH,} \mathrm{Maehlen} \mathrm{J.} \mathrm{Incidence} \mathrm{of} \mathrm{breast} \mathrm{cancer} \mathrm{in} \mathrm{Norway} \mathrm{and} \mathrm{Sweden} \mathrm{dur-}$ ing introduction of nationwide screening: prospective cohort study. BMJ 2004;328:921-4.

(Accepted 9 February 2005)

doi $10.1136 /$ bmj. $38398.469479 .8 \mathrm{~F}$

Screening and Test Evaluation Program, School of Public Health, University of Sydney, NSW 2006, Australia

Alexandra Barratt associate professor of epidemiology

Kirsten Howard research fellow health economics

Les Irwig professor of epidemiology

Glenn Salkeld associate professor of health economic

Nehmat Houssami clinical associate and honorary senior lecturer

Correspondence to: A Barratt alexb@health.usyd.edu.au 